\title{
The current situation in compliance with hand hygiene in dental surgeries in the Czech Republic
}

\author{
E SedlatáJurásková ${ }^{*}$, I Matoušková ${ }^{2}$ \\ From 3rd International Conference on Prevention and Infection Control (ICPIC 2015) \\ Geneva, Switzerland. 16-19 June 2015
}

\section{Introduction}

Implementation and compliance with hand hygiene in health care is different and depends on the type of separation. Hand Care is very important for the prevention of transmission of infectious agents between patients and dentist's protection against infection. Their microbial contamination occurs when bioaerosol contacts hands and during a treatment of the patient. The literature indicates that the degree of "compliance" in compliance with hand hygiene in a dental surgery is between $16-81 \%$, with an average of $40 \%$.

\section{Objectives}

The authors report in their work the current knowledge about the compliance policy guidance "Hand hygiene in health care" among dentists in the Czech Republic.

\section{Methods}

Epidemiological investigation was carried out by a single anonymous questionnaire in a total number of 54 respondents.

\section{Results}

Most were surprised to find that two dentists in private practice do not wash their hands before and after use non-sterile gloves.

We consider as highly positive finding that dentists in private dental surgeries in $88.89 \%$ used to disinfect hands disinfectants based on alcohol. In Faculty of Medicine and Dentistry, Palacký Univerzity Olomouc and Faculty Hospital Olomouc, which is under the supervision of the constitutional Hygienist, disinfectants for hands are in $100 \%$ alcohol-based.

'Department of Orthodontics, Faculty of Medicine and Dentistry, Palacký University Olomouc, Olomouc, Czech Republic

Full list of author information is available at the end of the article

\section{Conclusion}

Hand hygiene has long been considered one of the most important infection control measures to prevent health care-associated infections. It is necessary to educate health care workers in dentistry about hand care.

\section{Disclosure of interest}

None declared.

\section{Authors' details}

'Department of Orthodontics, Faculty of Medicine and Dentistry, Palacký University Olomouc, Olomouc, Czech Republic. ${ }^{2}$ Department of Preventive Medicine, Faculty of Medicine and Dentistry, Palacký University Olomouc, Olomouc, Czech Republic.

Published: 16 June 2015

\section{doi:10.1186/2047-2994-4-S1-P151}

Cite this article as: SedlatáJurásková and Matoušková: The current situation in compliance with hand hygiene in dental surgeries in the Czech Republic. Antimicrobial Resistance and Infection Control 2015 4(Suppl 1): P151.

Submit your next manuscript to BioMed Central and take full advantage of:

- Convenient online submission

- Thorough peer review

- No space constraints or color figure charges

- Immediate publication on acceptance

- Inclusion in PubMed, CAS, Scopus and Google Scholar

- Research which is freely available for redistribution 